\title{
VARIACIÓN ESTACIONAL E INTERANUAL DE LA DIETA DE LA LISA, Mugil cephalus Linnaeus, 1758, FRENTE A CALLAO $\left(12^{\circ} \mathrm{S}\right)$, en 2005 y 2013
}

\author{
SEASONAL AND INTERANNUAL VARIATION IN THE DIET OF THE STRIPED \\ MULLET, Mugil cephalus Linnaeus, 1758, FROM CALLAO $\left(12^{\circ} \mathrm{S}\right)$, in 2005 and 2013
}

\author{
César Fernández ${ }^{1}$
}

\begin{abstract}
Resumen
Se presenta un aporte a la ecología trófica de la lisa, Mugil cephalus. Se consideraron 3807 ejemplares de lisa capturados en la zona del Callao $\left(12^{\circ} \mathrm{S}\right)$ durante 2005 y 2013 , entre las 0 - 05 millas náuticas $(\mathrm{mn})$. Los ejemplares se agruparon en juveniles y adultos. Se analizaron dos estómagos por talla y se pesó cada contenido. Luego se agruparon en seis tallas por rangos con medio centímetro de diferencia. Los contenidos estomacales se filtraron y se obtuvieron dos submuestras (fitoplancton y zooplancton). Los análisis se estandarizaron y transformaron de número a carbono. Se utilizaron factores de conversión de carbono $\left(\mu \mathrm{g}^{-1}\right)$ individuales de fitoplancton y zooplancton. Los resultados indicaron que la dieta estuvo conformada por diatomeas de afloramiento (pelágicas y bentónicas), dinoflagelados (cosmopolitas y termófilos), silicoflagelados, tintínidos, copépodos, eufaúsidos, organismos ocasionales y restos orgánicos no identificados. El fitoplancton (99\%) dominó en número y $(46 \%)$ en carbono. La variación de la dieta respondió mejor a los cambios estacionales en relación con los interanuales y ontogénicamente las lisas juveniles y adultas no difirieron en sus presas planctónicas. Su plasticidad trófica es una de las adaptaciones que les han permitido vivir en ambientes antrópicos. Palabras clave: Mugil cephalus, lisa, dieta, ecología trófica, carbono, Callao, Perú.
\end{abstract}

\begin{abstract}
A contribution to the trophic ecology of the stripped mullet, Mugil cephalus, is described. The study considered 3807 stripped mullet specimens captured in the area of Callao $\left(12^{\circ} \mathrm{S}\right)$ in 2005 and in 2013, from 0 to 05 nautical miles $(\mathrm{nm})$. Samples were grouped into juveniles and adults. Two stomachs per size were analyzed and each of the contents were weighed. Then, they were grouped into six size ranges with half a centimeter apart. Stomach contents were filtered obtaining two subsamples (phytoplankton and zooplankton). Data were standardized and transformed from number to carbon. Individual carbon conversion factors $\left(\mu \mathrm{g}^{-1}\right)$ were used for phytoplankton and zooplankton. Results showed that the diet was composed of upwelling diatoms (pelagic and benthic), dinoflagellates (cosmopolitan and thermophilic), silicoflagellates, tintinnids, copepoda, euphausiacea, occasional organisms and unidentified organic remains. Phytoplankton (99\%) dominated in number and $(46 \%)$ carbon. Variation in the diet responded better to seasonal changes in relation to the interannual and ontogenically stripped mullets juveniles and adults did not differ in their planktonic prey. Its trophic plasticity is one of the adaptations that have allowed them to live in anthropic environments.
\end{abstract}

Key words: Mugil cephalus, striped mullet, diet, trophic ecology, carbon, Callao, Peru.

\section{Introducción.}

La investigación enfoca la variabilidad estacional e interanual de Mugil cephalus en Callao $\left(12^{\circ} \mathrm{S}\right)$ durante el período 2005-2013. El tema es importante porque permite actualizar los conocimientos de su ecología trófica, que sirven de información para uso académico y una importante aportación sobre su manejo, ya que presenta importantes desembarques en las pesquerías atesanales en la costa peruana; además de ser una buena fuente de proteína para el consumo humano directo.
Se sabe que, es una especie cosmopolita de hábitos bentopelágicos (Sánchez \& Zimic, 1973), los primeros trabajos sobre su alimentación fueron descriptivos, como los de (Kesteven, 1941; Hildebrandt, 1946; Koepcke, 1955), quienes reportaron la presencia de fango y algas; mientras que Llanos (1974) la catalogó como especie omnívora e iliófaga. Otros determinaron presas zooplanctónicas (Hendricks, 1961; Thomson, 1964) con ingestión ocasional de copépodos, probablemente provenientes de algas. Por su parte, 
Gonzáles \& Álvarez-Lajonchere (1978) la clasificaron como detritívora, que consume partículas inorgánicas, detrito orgánico y diatomeas, con variaciones de acuerdo con el área. Collins (1981) estudió los ítems alimenticios y presentó hasta cinco categorías: diatomeas, algas filamentosas, otras algas, detritus y partículas sedimentadas. A su vez, Franco \& Bashirullah (1992) observaron que la principal característica que define el comportamiento alimenticio de los mugílidos es la facilidad para adaptarse y subsistir con alimentos de diverso origen, según las condiciones en el que desarrolle

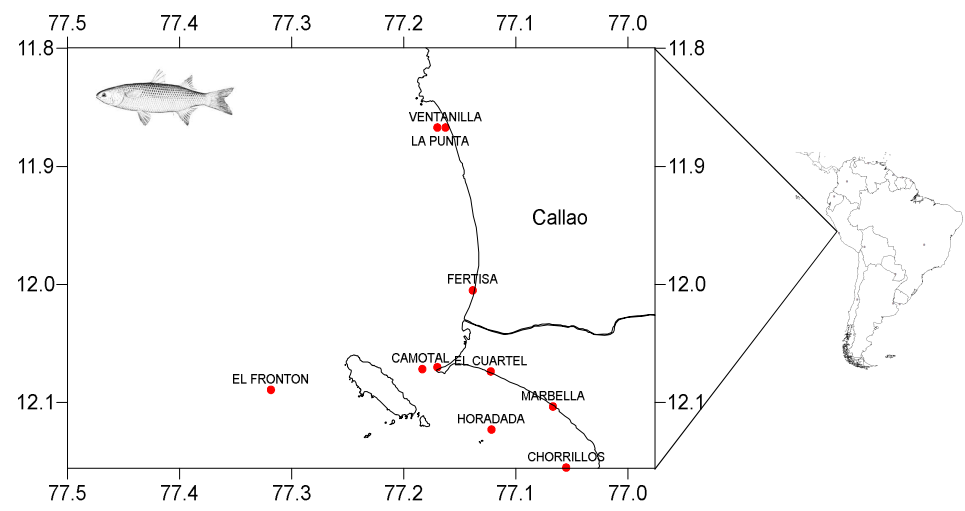

Figura 1. Áreas de muestreo.

su ciclo vital. Un aporte interesante fue el de Verdiell et al., (2007), quienes estudiaron mugílidos juveniles de tres especies, cuya dieta fue omnívora, tanto de origen animal como vegetal.

El presente estudio tiene como objetivos: (i) determinar la composición de la dieta, (ii) analizar la variación estacional, (iii) analizar la variación interanual y (iv) determinar la variación ontogénica de la dieta.

\section{Materiales y métodos.}

Área de estudio.

El área del Callao, está localizada entre los $12^{\circ} 00^{\prime}-$ 12³0', situada en Lima; capital del Perú. Sostiene una intensa actividad antropogénica, principalmente el puerto; un muelle artesanal pesquero, además de la desembocadura de un colector; con aguas residuales domésticas y/o industriales.

La pesca de la lisa la realiza la flota artesanal con embarcaciones de poca capacidad de carga: botes y chalanas utilizando redes de cerco, cortina, chinchorro y otras artes de pesca. El zarpe es variable, pudiendo ser por la mañana o en la tarde (Tabla 1). El tiempo que transcurre hasta el arribo es todo un día, aunque también depende de la disponibilidad del recurso. El recurso obtenido es almacenado en cajas plásticas conservadas con hielo hasta su posterior comercialización en el terminal pesquero. La muestra biológica se adquirió durante el desembarque, tomando una muestra aleatoria de la pesca (juveniles y adultos).
El observador de campo de Imarpe entrevista al pescador, obteniendo información de la pesca: área, captura total $(\mathrm{Kg})$, fauna acompañante, profundidad captura (bz), distancia costa (mn), arte de pesca. Las áreas de pesca donde se capturó este recurso fueron: Marbella, El Frontón, La Fertiza, Camotal, Horadada, Chorrillos, Base Naval, La Punta, Los Tanques, El Cuartel y Ventanilla (Figura 1).

Muestreo del recurso.

La muestra es llevada al Imarpe donde se lleva a cabo un muestreo biométrico y biológico, obteniendo dos estómagos por talla y preservándolos en alcohol al $10 \%$ hasta su posterior análisis en el laboratorio.

Colección de estómagos.

Se extrajeron 3807 estómagos de lisa durante el período 2005 al 2013. La periodicidad de la colecta fue variable y depende principalmente del presupuesto así como la disponibilidad del recurso. El muestreo puede ser 1 o 2 veces por semana, totalizando al mes de 3 a 6 colectas; pudiendo comenzar a inicios de año (enero), durante el verano o más adelante hasta diciembre.

El seguimiento y evaluación de este recurso (Imarpe), agrupa los individuos de lisa en juveniles (menores de $37 \mathrm{~cm}$ ) y adultos (mayores de $37 \mathrm{~cm}$ ), tomando los $37 \mathrm{~cm}$ como patrón, criterio tomado del primer desove de esta especie y con el cual norma el Ministerio de Pesquería R.M. $\quad N^{\circ}$ 209-2001-PE (Aprueban relación de tallas mínimas de captura y tolerancia máxima- 21 junio 2001). Sin embargo, últimos estudios del Laboratorio de Reproducción (no publicados), vienen elaborando una nueva escala de

Tabla 1. Captura de la muestra biológica, Mugil cephalus en el Callao.

\begin{tabular}{|c|c|c|c|c|c|}
\hline Embarcaciones & Área de pesca & Capacidad de bodega (ton) & Arte de pesca & Zarpe & Arribo \\
\hline Zapato & $\begin{array}{l}\text { Marbella, el } \\
\text { Frontón, La }\end{array}$ & $<=0.5$ & cortina, chinchorro, otros & 06:00-08:00 & $13: 00-17: 00$ \\
\hline Chalana & $\begin{array}{c}\text { Fertiza, Camotal, } \\
\text { Horadada, }\end{array}$ & $0.6-1.5$ & cortina, chinchorro, cerco y otros & 06:00-08:00 & $13: 00-17: 00$ \\
\hline Bote & $\begin{array}{l}\text { Chorillos, Base } \\
\text { Naval, La Punta, }\end{array}$ & $1.6-5$ & cortina, cerco, chinchorro y otros & $16: 00-17: 00$ & 04:00-08:00 \\
\hline & $\begin{array}{l}\text { Los Tanques, El } \\
\text { Cuartel y }\end{array}$ & & & 00:00 & $06: 00$ \\
\hline Lancha & Ventanilla. & $>5$ & cerco, cortina, otros & 19:00 & $22: 00$ \\
\hline
\end{tabular}




\section{FERNÁNDEZ}

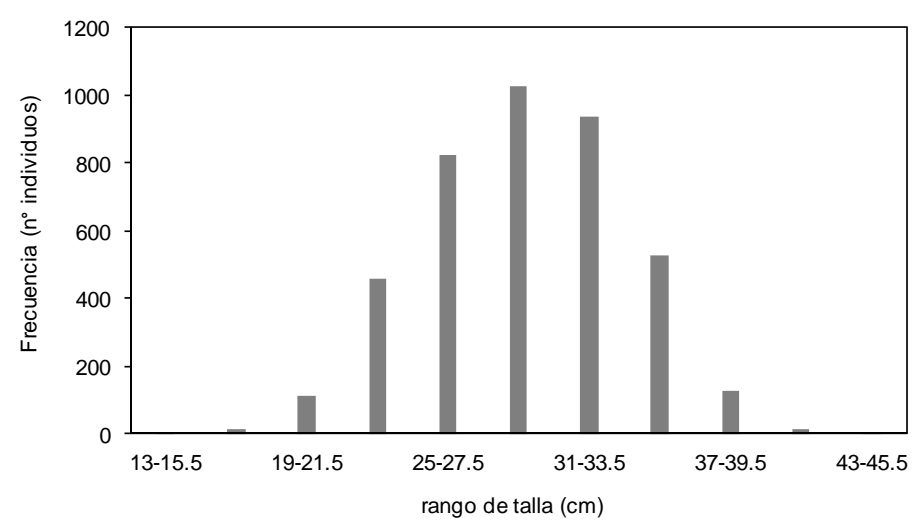

Figura 2. Distribución de frecuencias de las tallas de $M$. cephalus (2005 al 2013 de Callao).

zooplancton). Se analizaron los contenidos estomacales de lisas entre 13,0 y 45,0 cm de longitud total. La lectura del fitoplancton se realizó con un microscopio compuesto (modelo Nikon Eclipse E400). El análisis de la fracción zooplanctónica se realizó con un microscopio estereoscopio SMZ 800 Nikon. Para la determinación taxonómica se utilizaron los trabajos de Cupp (1943), Balech (1988), Steidinger \& Tangen (1996), Schiller (1971) y Boltovskoy (1981). El análisis cuantitativo consistió en determinar la composición del contenido estomacal al menor taxón posible, con el método numérico de Berg (1979) e Hyslop (1980).

La información fue digitada y los datos maduración, considerando $24 \mathrm{~cm}$ adultos. Por este motivo, en el presente manuscrito se prefirió no agrupar los rangos de talla en juveniles y adultos.

Procesamiento en el laboratorio.

El contenido estomacal de cada individuo se pesó en una balanza analítica (marca Sartorius) con precisión 0,001 g; agrupándose por rangos de talla al medio cm: por ejemplo 13.0 a $15.5 \mathrm{~cm}$ reunió seis tallas: $13.0,13.5,14.0,14.5,15.0$ y 15.5 . Luego el contenido estomacal se filtró con tamices de 75 y 300 $\mu$ obteniéndose dos submuestras (fitoplancton $\mathrm{y}$ numéricos se estandarizaron y fueron transformados a unidades de carbono. Para el fitoplancton, se aplicaron factores de conversión de contenido de carbono utilizando ecuaciones dadas en Menden-Deur y Lessard (2000) y Verity y Langdon (1984); por su parte el zooplancton se estimó a partir de literatura, Alexandrov (2001), Deibel (1986), James (1987), Van der Lingen (2002), Parsons et al., (1984) y Sameoto (1971) y mediciones realizadas en Imarpe. Los resultados de la dieta se expresaron en términos de carbono, el cual presenta la contribución energética de
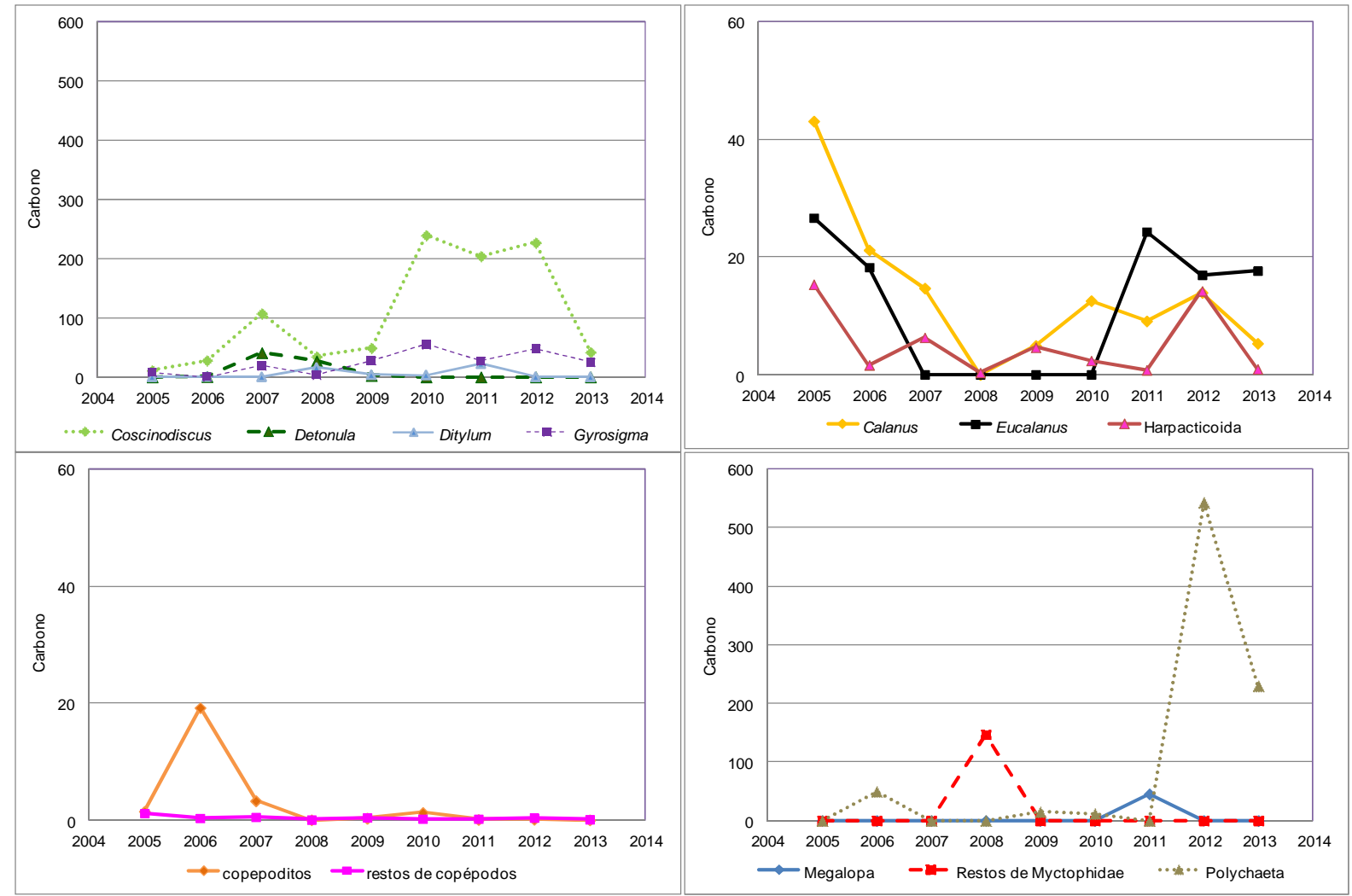

Figura 3. Variación del contenido de carbono $\left(\mu \mathrm{g}\right.$. ind $\left.{ }^{-1}\right)$ de las principales presas de M. cephalus (20052013 de Callao). 
Tabla 3. Prueba de Kruskall-Wallis del contenido de carbono entre estaciones del año en Mugil cephalus.

\begin{tabular}{cccccc}
\hline $\begin{array}{c}\text { Grupos } \\
\text { dietarios }\end{array}$ & Estación & $\mathrm{N}$ & $\begin{array}{c}\text { Rango } \\
\text { promedio }\end{array}$ & Chi cuadrado & p valor \\
\hline \multirow{2}{*}{$\begin{array}{c}\text { Diatomeas } \\
\text { pelágicas }\end{array}$} & Otoño & 186 & 348.92 & \multirow{2}{*}{36.041} & \multirow{2}{*}{0.000} \\
& Invierno & 254 & 431.85 & & \\
\cline { 2 - 7 } & Primavera & 213 & 354.96 & & \\
\cline { 2 - 6 } Diatomeas & Verano & 33 & 146.06 & & 0.000 \\
bentónicas & Onvierno & 161 & 213.39 & 18.02 & \\
& Primavera & 102 & 175.28 & & \\
\cline { 2 - 6 } & Verano & 53 & 236.25 & & \\
& Otoño & 110 & 193.24 & & \\
Copépodos & Invierno & 128 & 168.59 & & \\
& Primavera & 100 & 212.79 & & \\
\cline { 2 - 6 } & & & & & \\
\hline
\end{tabular}

las presas en el pez.

Se obtuvieron los pesos promedio de contenido estomacal, agrupando los pesos individuales por rango de tallas. Cabe señalar que el contenido estomacal ocasionalmente trae arena, para ello se está considerando la mejor manera de separación pudiendo ser con tamices más finos $(63 \mu)$, sedimentación, etc.

Análisis Estadísticos.

A los datos se les realizó pruebas de normalidad (Kolmogorov-Smirnov a y Shapiro-Wilk) concluyendo que las variables estudiadas no tienen distribución normal, además se realizaron las pruebas de homogeneidad de varianza (Estadístico de Levene) determinando que las varianzas son diferentes.

El Escalamiento No métrico Multi-dimensional (NMDS) se usó para graficar biplots de fechas y grupos dietarios, a partir de matrices de pesos de contenido estomacal ordenados en objetos (años o meses) y dimensiones (grupos dietarios). Se utilizó el NMDS debido a que es la técnica recomendada para datos biológicos caracterizados por presentar relaciones no lineales entre las dimensiones (Borcard et al., 2011).

Además se utilizó el Análisis de Componentes Principales (PCA) el cual analiza los coeficientes en las combinaciones lineales de las variables.
Los datos se transformaron mediante Log $(x+1)$ debido a la alta variabilidad de los ítems planctónicos, antes de ejecutar los análisis NMDS y PCA con ayuda del programa Primer versión 6.

Se realizaron pruebas Kruskall Wallis, para verificar si existen diferencias en más de dos grupos, es una prueba no paramétrica (Theodorsson-Norheim, 1986), además se realizó la prueba de Comparaciones múltiples dándole un rigor estadístico a los análisis ya obtenidos. Se utilizó el programa $\mathrm{R}$ versión 3.1.1. y SPSS.

\section{Resultados.}

Composición de la dieta.

El mayor esfuerzo de muestreo estuvo concentrado en el rango de talla de 22.0 a 36.5 $\mathrm{cm}$, representando el $94.0 \%$ del total de la muestra obtenida (Figura 2). La distribución de frecuencia de la dieta estuvo conformada por 25

Tabla 4. Prueba de comparaciones múltiples de Kruskall-Wallis del contenido de carbono entre estaciones del año en Mugil cephalus.

\begin{tabular}{cccc}
\hline $\begin{array}{c}\text { Grupos } \\
\text { dietarios }\end{array}$ & Estación & $\begin{array}{c}\text { Estadístico de } \\
\text { Prueba }\end{array}$ & P valor \\
\hline \multirow{2}{*}{$\begin{array}{c}\text { Diatomeas } \\
\text { pelágicas }\end{array}$} & Ver - Inv & -140.713 & 0.000 \\
& Otoñ - Inv & -82.93 & 0.000 \\
& Primv - Inv & 76.886 & 0.001 \\
\cline { 2 - 4 } Diatomeas & Ver - Inv & -67.328 & 0.014 \\
bentónicas & Ver - Otoñ & -76.497 & 0.005 \\
& Primv - Otoñ & 47.278 & 0.020 \\
\cline { 2 - 4 } Copepodos & Inv - Primv & -44.196 & 0.020 \\
& Inv - Vera & 67.652 & 0.001 \\
\hline
\end{tabular}

diatomeas pelágicas $(29 \%), 10$ diatomeas bentónicas (11\%), 7 dinoflagelados cosmopolitas (8\%), 2 dinoflagelados termófilos (2\%), 2 silicoflagelados (2\%), 6 tintínidos (7\%), 16 copépodos (18\%) y 19 organismos ocasionales $(22 \%)$ como poliquetos, larvas de cirrípedos, huevos de anchoveta, eufaúsidos, zoeas, bivalvos, gasterópodos, ostrácodos, Semimytilus algosus (Tabla 2).

Tabla 5. Variación interanual del contenido de carbono promedio $\left(\mu \mathrm{g}\right.$. ind $\left.{ }^{-1}\right)$ de los grupos dietarios de Mugil cephalus.

\begin{tabular}{|c|c|c|c|c|c|c|c|}
\hline AÑO & DIATOMEAS & DINOFLAGELADOS & SILICOFLAGELADOS & COPEPODOS & EUFAÚSIDOS & $\begin{array}{l}\text { HUEVOS DE } \\
\text { ANCHOVETA }\end{array}$ & $\begin{array}{l}\text { OTRAS } \\
\text { PRESAS }\end{array}$ \\
\hline 2005 & 2390.7 & 2422.0 & 130.1 & 14138.6 & 0.0 & 0.0 & 0.2 \\
\hline 2006 & 4357.6 & 2619.4 & 199.1 & 13325.4 & 0.0 & 0.0 & 4618.8 \\
\hline 2007 & 18164.8 & 2479.7 & 1195.0 & 5393.8 & 0.0 & 0.0 & 12.8 \\
\hline 2008 & 13161.3 & 2166.2 & 82.3 & 217.3 & 0.0 & 0.0 & 33280.1 \\
\hline 2009 & 14886.3 & 2668.4 & 83.2 & 3776.7 & 0.0 & 950.9 & 3012.5 \\
\hline 2010 & 38548.5 & 2154.0 & 29.6 & 1954.1 & 18972.6 & 0.0 & 2462.6 \\
\hline 2011 & 28111.9 & 676.5 & 33.6 & 2854.4 & 0.0 & 44.9 & 12227.2 \\
\hline 2012 & 31697.2 & 23720.9 & 45.5 & 9425.2 & 181439.5 & 312.6 & 96795.4 \\
\hline 2013 & 6411.3 & 289.0 & 102.5 & 3732.2 & 0.0 & 77.6 & 26279.3 \\
\hline
\end{tabular}




\section{FERNÁNDEZ}

Ecol. apl. Vol. $13 \mathrm{~N}^{\circ}$ 2, pp. 211-223

Tabla 6. Prueba de Kruskall-Wallis del contenido de carbono entre años en Mugil cephalus.

\begin{tabular}{|c|c|c|c|c|c|}
\hline $\begin{array}{c}\text { Grupos } \\
\text { dietarios }\end{array}$ & Año & $\mathrm{N}$ & $\begin{array}{l}\text { Rango } \\
\text { promedio }\end{array}$ & Chi cuadrado & $\mathrm{p}$ valor \\
\hline \multirow{9}{*}{$\begin{array}{l}\text { Diatomeas } \\
\text { pelágicas }\end{array}$} & 2005 & 65 & 332.83 & \multirow{9}{*}{20.119} & \multirow{9}{*}{0.010} \\
\hline & 2006 & 72 & 349.94 & & \\
\hline & 2007 & 86 & 389.76 & & \\
\hline & 2008 & 104 & 320.68 & & \\
\hline & 2009 & 74 & 396.27 & & \\
\hline & 2010 & 104 & 426.50 & & \\
\hline & 2011 & 80 & 399.13 & & \\
\hline & 2012 & 88 & 343.80 & & \\
\hline & 2013 & 70 & 383.30 & & \\
\hline \multirow{9}{*}{$\begin{array}{l}\text { Diatomeas } \\
\text { bentónicas }\end{array}$} & 2005 & 37 & 186.81 & \multirow{9}{*}{14.457} & \multirow{9}{*}{0.071} \\
\hline & 2006 & 33 & 199.92 & & \\
\hline & 2007 & 43 & 192.41 & & \\
\hline & 2008 & 52 & 161.66 & & \\
\hline & 2009 & 36 & 206.88 & & \\
\hline & 2010 & 56 & 228.70 & & \\
\hline & 2011 & 39 & 199.44 & & \\
\hline & 2012 & 66 & 227.31 & & \\
\hline & 2013 & 38 & 183.57 & & \\
\hline \multirow{9}{*}{ Copépodos } & 2005 & 70 & 207.53 & \multirow{9}{*}{35.558} & \multirow{9}{*}{0.000} \\
\hline & 2006 & 59 & 239.92 & & \\
\hline & 2007 & 69 & 194.05 & & \\
\hline & 2008 & 18 & 90.17 & & \\
\hline & 2009 & 27 & 235.76 & & \\
\hline & 2010 & 34 & 162.78 & & \\
\hline & 2011 & 28 & 213.73 & & \\
\hline & 2012 & 63 & 172.18 & & \\
\hline & 2013 & 23 & 183.00 & & \\
\hline
\end{tabular}

Del fitoplancton destacaron, Coscinodiscus perforatus (104.794 $\left.\mu \mathrm{g} / \mathrm{ind}^{-1}\right)$, Detonula pumila $(7.872$ $\left.\mu \mathrm{g} / \mathrm{ind}^{-1}\right)$, Ditylum brightwellii $\left(5.066 \mu \mathrm{g} / \mathrm{ind}^{-1}\right)$, Gyrosigma sp.(23.697 $\left.\mu \mathrm{g} / \mathrm{ind}^{-1}\right)$, del zooplancton: Calanus sp.(13.589 $\left.\mu \mathrm{g} / \mathrm{ind}^{-1}\right)$, Eucalanus sp.(11.531 $\mu \mathrm{g} /$ ind $\left.^{-1}\right)$, Harpatocoida $\left(5.163 \mu \mathrm{g} / \mathrm{ind}^{-1}\right)$, Copepoditos $\left(2.857 \mu \mathrm{g} /\right.$ ind $\left.^{-1}\right)$, restos de copépodos $\left(0.378 \mu \mathrm{g} / \mathrm{ind}^{-1}\right)$, megalopas $\left(5.105 \mu \mathrm{g} / \mathrm{ind}^{-1}\right)$ restos de myctophidae $\left(16.352 \mu \mathrm{g} / \mathrm{ind}^{-1}\right)$ y polychaeta $\left(94.422 \mu \mathrm{g} / \mathrm{ind}^{-1}\right)$, (Figura 3).

Variación estacional.

La composición porcentual de la dieta presentó diferencias estacionales. Dominaron las diatomeas pelágicas (otoño, invierno y parte de primavera), otras presas (invierno y primavera) y dinoflagelados (verano); además de la presencia de eufaúsidos (finales de primavera) y diatomeas bentónicas (otoño, invierno y primavera) (Figura 4).

El contenido de carbono de los grupos dietarios también presentó diferencias estacionales (Tablas 3 y 4).
Las diatomeas presas pelágicas presentaron diferencias significativas entre el invierno y las estaciones de verano $(\mathrm{p}<0.01)$, otoño $(\mathrm{p}<0.01)$ y primavera $(\mathrm{p}<0.01)$.

Las diatomeas presas bentónicas presentaron diferencias significativas entre el verano y las estaciones de invierno $(\mathrm{p}<0.01)$ y de otoño $(\mathrm{p}<0.01)$. También se encontraron diferencias significativas entre la primavera y el otoño $(\mathrm{p}<0.01)$.

Los copépodos presas presentaron diferencias entre el invierno y la primavera $(\mathrm{p}<0.05)$ y el verano $(\mathrm{p}<0.01)$.

Variación interanual.

Durante el periodo 2005 al 2013, la composición porcentual de la dieta de la lisa fue variable; destacaron las diatomeas pelágicas (2007 y del 2009-2011), los copépodos (2005-2006), otras presas (2008 y 2013) y eufaúsidos (2012). El 2008 se diferenció con respecto a los otros años, debido a la importancia de los restos de myctophidae (56\%) y en el 2012 destacaron los eufaúsidos (59\%) (Figura 5) (Tabla 5).

El contenido de carbono de los grupos dietarios también presentó diferencias interanuales (Tabla 6 y 7).

Las diatomeas presas pelágicas presentaron diferencias significativas entre los años 2008 y 2010 $(\mathrm{p}<0.05)$. Las diatomeas bentónicas no presentaron diferencias significativas ( $\mathrm{p}>0.05)$.

No se puede rechazar la $\mathrm{H}_{\mathrm{o}}$ nula, sin embargo no existe suficiente evidencia que afirme que la variación de las diatomeas presas bentónicas es igual por año.

Los copépodos presentaron diferencias significativas entre el año 2008 y los años 2005 $(\mathrm{p}<0.01), 2006(\mathrm{p}<0.01), 2007 \quad(\mathrm{p}<0.01), 2009$ $(\mathrm{p}<0.01)$ y $2011(\mathrm{p}<0.05)$.

Variación ontogénica.

La composición porcentual de la dieta por rangos de talla no fue uniforme, las lisas juveniles y adultas se alimentaron indistintamente de diatomeas, copépodos y otras presas. Las de talla 13.0 a $15.5 \mathrm{~cm}$ consumieron principalmente diatomeas y las de 43.0 a $45.5 \mathrm{~cm}$ ingirieron dinoflagelados y copépodos; mientras que las de 19.0 a $39.5 \mathrm{~cm}$ tuvieron un amplio rango de presas (diatomeas, dinoflagelados, copépodos, eufaúsidos, además de polychaeta, restos de myctophidae, larvas de pez, megalopas, bivalvia, gastropoda; las de 16.0 a $18.5 \mathrm{~cm}$ consumieron principalmente restos de myctophidae y entre las de

Tabla 7. Prueba de comparaciones múltiples de Kruskall-Wallis del contenido de carbono entre años en Mugil cephalus.

\begin{tabular}{cccc}
\hline $\begin{array}{c}\text { Grupo } \\
\text { dietario }\end{array}$ & Años & $\begin{array}{c}\text { Estadístico } \\
\text { de Prueba }\end{array}$ & P valor \\
\hline Diatomeas pelágicas & $2008-2010$ & -105.827 & 0.014 \\
\hline
\end{tabular}


Tabla 8. Prueba de Kruskall-Wallis del contenido de carbono entre rangos de tallas en Mugil cephalus.

\begin{tabular}{|c|c|c|c|c|c|}
\hline $\begin{array}{c}\text { Grupos } \\
\text { dietarios }\end{array}$ & Talla $(\mathrm{cm})$ & $\mathrm{N}$ & $\begin{array}{l}\text { Rango } \\
\text { promedio }\end{array}$ & Chi cuadrado & $\mathrm{p}$ valor \\
\hline \multirow{7}{*}{$\begin{array}{l}\text { Diatomeas } \\
\text { pelágicas }\end{array}$} & $13-21.5$ & 34 & 347.96 & \multirow{7}{*}{7.895} & \multirow{7}{*}{0.246} \\
\hline & $22-24.5$ & 86 & 337.06 & & \\
\hline & $25-27.5$ & 143 & 374.87 & & \\
\hline & $28-30.5$ & 164 & 384.72 & & \\
\hline & $31-33.5$ & 158 & 392.95 & & \\
\hline & $34-36.5$ & 112 & 376.87 & & \\
\hline & $37-42.5$ & 46 & 317.01 & & \\
\hline \multirow{7}{*}{$\begin{array}{l}\text { Diatomeas } \\
\text { bentónicas }\end{array}$} & $16-21.5$ & 16 & 139.09 & \multirow{7}{*}{6.76} & \multirow{7}{*}{0.344} \\
\hline & $22-24.5$ & 43 & 187.63 & & \\
\hline & $25-27.5$ & 82 & 192.59 & & \\
\hline & $28-30.5$ & 83 & 211.16 & & \\
\hline & $31-33.5$ & 84 & 206.23 & & \\
\hline & $34-36.5$ & 63 & 205.44 & & \\
\hline & $37-45.5$ & 28 & 211.50 & & \\
\hline \multirow{7}{*}{ Copépodos } & $16-21.5$ & 17 & 224.32 & \multirow{7}{*}{4.132} & \multirow{7}{*}{0.659} \\
\hline & $22-24.5$ & 45 & 197.18 & & \\
\hline & $25-27.5$ & 75 & 196.55 & & \\
\hline & $28-30.5$ & 89 & 204.00 & & \\
\hline & $31-33.5$ & 83 & 198.38 & & \\
\hline & $34-36.5$ & 58 & 183.34 & & \\
\hline & $37-45.5$ & 24 & 164.69 & & \\
\hline
\end{tabular}

de 40 ítems-presa (diatomeas, dinoflagelados, silicoflagelados, tintínidos, copépodos, polychaeta y otros). Finalmente, el tercer grupo con lisas de 43.0 a $45.5 \mathrm{~cm}$, consumieron el dinoflagelado Protoperidinium sp. y restos de copépodos.

Los pesos promedio de contenido estomacal por rangos de talla (16.0 a $39.5 \mathrm{~cm}$ LT) presentaron un patrón de mayor contenido estomacal a mayor rango de talla (Figura 8). En particular, desde el 2005 al 2013, los pesos no superaron $1 \mathrm{~g}$, excepto en el 2009, en el que los individuos de 34.0 a $36.5 \mathrm{~cm}$ y 37.0 a $39.5 \mathrm{~cm}$ LT alcanzaron 1,07 y $1,38 \mathrm{~g}$, respectivamente. Estos datos podrían ser más precisos si se usa una técnica que permita separar el alimento de la parte inorgánica.

El análisis NMDS presentó una distribución espacial por mes (Figura 9), con un stress de 0.07; donde el verano se segregó, mientras que finales del otoño se reunió con invierno y comienzos de primavera. Además se analizó la variabilidad por año (Figura 10), con un stress de 0.12; observando una tendencia con asociaciones: 2005-2006, 2007 con 2009-2011; mientras que 2008 y 2013 son independientes.

El análisis PCA enseño la asociación de 31.0 a $42.5 \mathrm{~cm}$ destacaron los eufaúsidos (Figura 6) (Tabla 8).

El contenido de carbono entre rangos de tallas no presentó diferencias significativas $(\mathrm{p}>0.05)$, tanto en diatomeas pelágicas, diatomeas bentónicas y copépodos (Tabla 9).

El análisis de cluster (Figura 7) presentó tres grupos de tallas (a un nivel de similaridad de $20 \%$ ): el primer grupo, con las lisas de 13.0 a $18.5 \mathrm{~cm}$, se alimentaron únicamente de Coscinodiscus sp.; el segundo grupo, con lisas de 19,0 a $42.5 \mathrm{~cm}$, compartieron 12 ítems-presa (diatomeas, dinoflagelados, copépodos y polychaeta). Cabe señalar que un subgrupo de 19.0 a 39.5 coincidió en la ingesta los rangos de talla con los grupos dietarios (Figura 11). El primer componente presentó $64 \%$ de variabilidad. El cuadrante de arriba hacia la izquierda agrupó diatomeas pelágicas, diatomeas bentónicas, dinoflagelados, silicoflagelados, tintínidos, copépodos y otras presas con los individuos de 19.0 a $30.5 \mathrm{~cm}$; mientras que en el cuadrante de abajo solo se encontraron los huevos de anchoveta y eufaúsidos con los de 31.0 a $39.5 \mathrm{~cm}$. Además segregados de derecha hacia abajo los de 13.0 a15.5 con los de 43.0 a 45.5 $\mathrm{cm}$.

Tabla 9. Contenido de carbono promedio $\left(\mu \mathrm{g}\right.$. ind $\left.^{-1}\right)$ de los grupos dietarios de Mugil cephalus por rangos de tallas.

\begin{tabular}{cccccccc}
\hline & & & & & \multicolumn{2}{c}{ HUEVOS DE } & OTRAS \\
TALLAS & DIATOMEAS & DINOFLAGELADOS & SILICOFLAGELADOS & COPEPODOS & EUFAÚSIDOS & ANCHOVETA & PRESAS \\
\hline $13-15$ & 21.1 & 0.0 & 11.2 & 0.0 & 0.0 & 0.0 & 0.0 \\
$16-18$ & 117.0 & 1261.1 & 9.5 & 56.3 & 0.0 & 0.0 & 9303.2 \\
$19-21$ & 15661.1 & 3608.5 & 785.9 & 7081.9 & 0.0 & 0.0 & 13254.5 \\
$22-24$ & 12039.2 & 2936.3 & 193.7 & 5507.4 & 0.0 & 0.0 & 17151.0 \\
$25-27$ & 25732.2 & 4034.3 & 145.5 & 10305.1 & 0.0 & 38.1 & 7214.4 \\
$28-30$ & 31151.8 & 2822.2 & 179.5 & 12732.9 & 23552.2 & 378.7 & 22341.5 \\
$31-33$ & 31936.3 & 3094.0 & 106.6 & 7691.4 & 69566.4 & 367.1 & 29494.5 \\
$34-36$ & 34077.2 & 21376.4 & 49.2 & 5358.6 & 65422.9 & 195.4 & 12392.5 \\
$37-39$ & 6862.5 & 37.8 & 0.0 & 66.6 & 41870.7 & 0.0 & 46834.2 \\
$40-42$ & 131.2 & 14.0 & 0.0 & 21.2 & 0.0 & 0.0 \\
$43-45$ & 157729.5 & & & & 0.0 & 0.0 \\
\hline
\end{tabular}




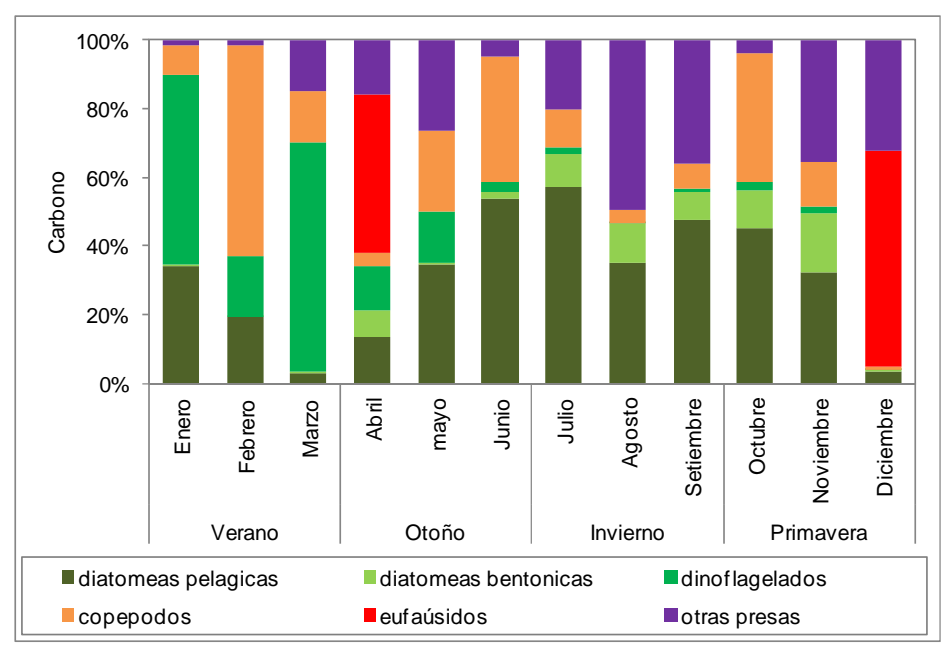

Figura 4. Variación estacional de la composición de la dieta (\% carbono) de M. cephalus (2005 al 2013 de Callao). diverso origen y poco exigente en sus requerimientos nutricionales (Franco \& Bashirullah 1992).

Variación estacional.

La variación estacional de la dieta, presentó diferencias en la ocurrencia de los grupos dietarios. Prácticamente en las cuatro estaciones destacaron las diatomeas y dinoflagelados en el contenido estomacal, decayendo en otoño y finales de primavera; sin embargo las mayores abundancias de fitoplancton en el mar se presentan entre la primavera y el otoño y menor cantidad en invierno (Ochoa et al., 1986). Las diferencias temporales podrían deberse a una mayor electividad de fitoplancton por la lisa en el invierno.

Variación interanual.

La composición porcentual de la dieta

\section{Discusión.}

Composición de la dieta.

Se determinó que las diatomeas pelágicas dominaron, asociadas a las bentónicas; además de los copépodos calanoideos y eufaúsidos, resultados que contrastan con lo encontrado por Odum (1970), Wells (1984), Romer \& McLachlan (1986), quienes observaron la fuerte afinidad de la lisa por presas bentónicas y en menor grado por las pelágicas (Romer \& McLachlan, 1986; Drake \& Gallego, 1984; Odum, 1968; Cardona, 1990); en tanto, la presencia de presas zooplanctónicas indicaría su carácter oportunista con una alta tasa de ingestión de presas abundantes y una baja eficiencia de asimilación (Odum 1970), permitiéndole sobrevivir con alimentos de

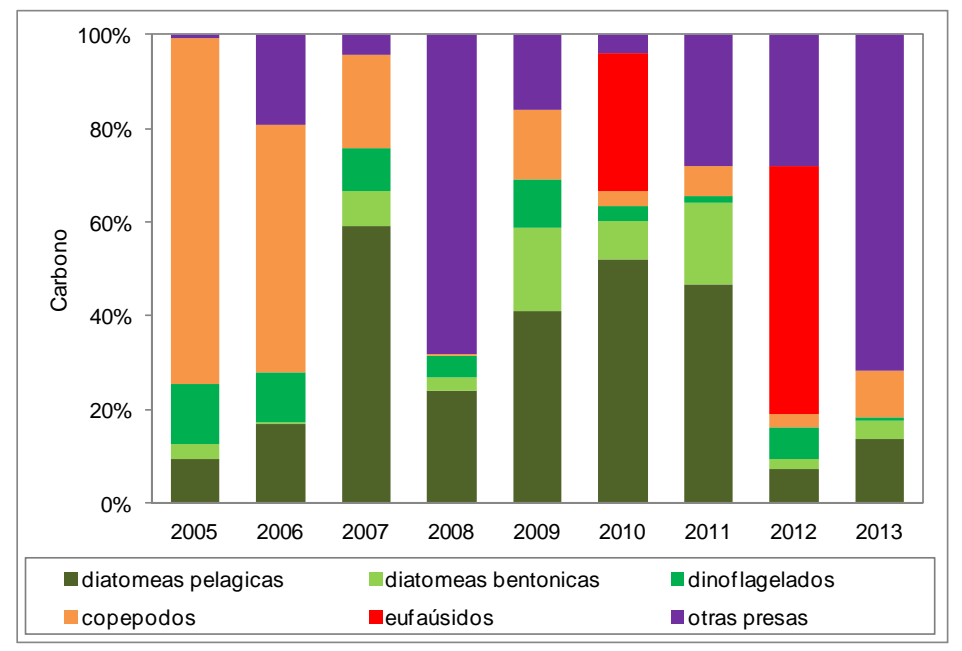

Figura 5. Variación interanual de la composición de la dieta (\% carbono) de M. cephalus (2005 al 2013 de Callao).

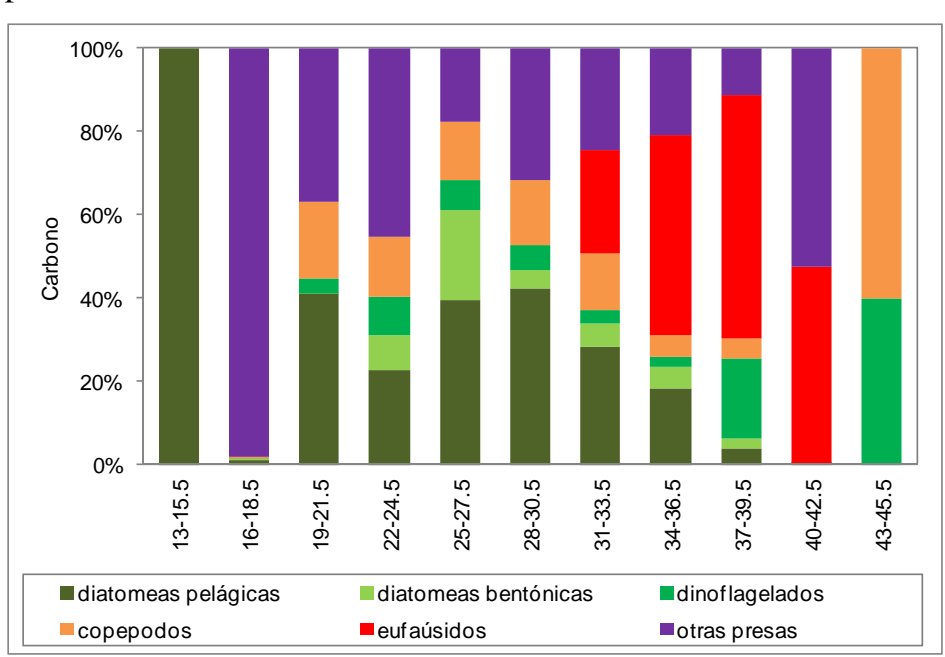

Figura 6. Variación ontogénica por rangos de tallas de la composición de la dieta (\% carbono) de M. cephalus (2005 al 2013 de Callao). presentó más del $50 \%$ de fitoplancton en los años 2007, 2009, 2010 y 2011. Estos años coinciden con la presencia de eventos La Niña durante los años 2007, inicios del 2009 y 2010-11; favoreciendo los procesos de afloramiento costero en el Callao (IMARPE, 2005, 2006, 2007, 2008, 2009, 2010, 2011, 2012, ERFEN, 2013).

Las principales presas consumidas fueron Coscinodiscus perforatus y Gyrosigma sp. diatomeas que presentan altas biomasas en Callao; donde la primera fue abundante e indicadora de contaminación en esta área durante el 2006 al 2011 (IMARPE, 2011), luego Ceratium spp. es un dinoflagelado que comúnmente en esta área puede ocasionar mareas rojas. Del zooplancton consumió ocasionalmente copépodos calanoideos destacando Calanus sp., Eucalanus sp. y 


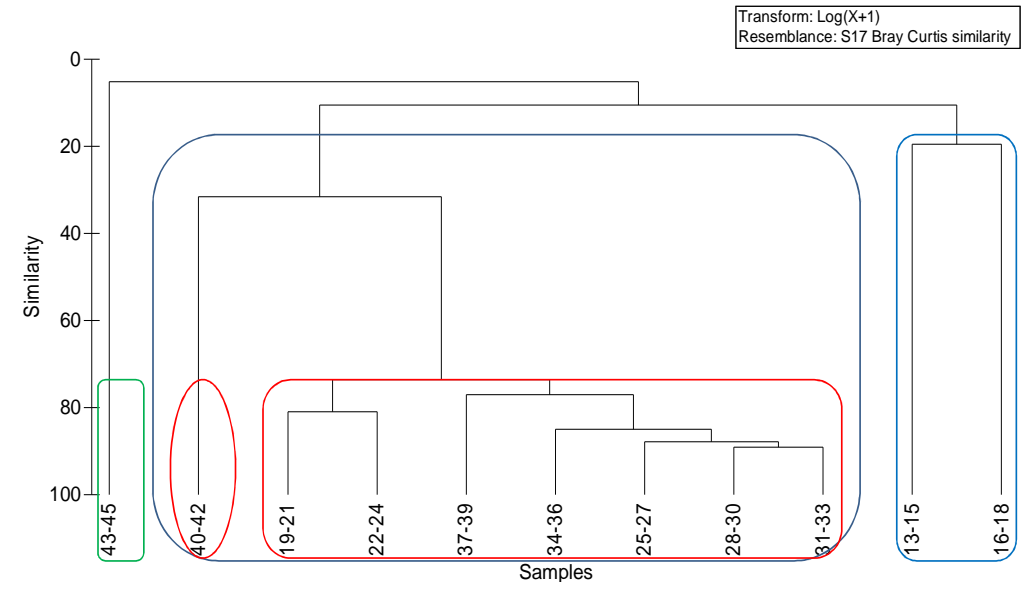

Figura 7. Análisis de cluster entre rangos de talla de $M$. cephalus (2005 al 2013 de Callao). micrófagos y la entrada a los estuarios en diferentes momentos de acuerdo a los períodos de desove (Blaber et al., 1997).

La plasticidad ecológica que presenta la lisa le brinda la capacidad de consumir una gran variedad de presas (Fernández-Delgado et al., 2000; Cardona, 2001), debido a adaptaciones en el aparato bucal y digestivo; disminución de la dentición, engrosamiento de las paredes musculares del estómago y el alargamiento del intestino (Drake et al., 1984); tamaño de la boca, permitiéndole ingerir presas relativamente grandes. Además la forma particular de tomar el alimento

Harpatocoida; sin embargo, en el ambiente, Acartia sp., Paracalanus sp. y Centropages sp. alcanzaron los niveles de abundancia más altos, Quesquen \& Ayón 2011 (no publicado). Respecto a esto, ElMarakby et al., (2006) mencionan que la lisa no consume alimentos de forma aleatoria, selecciona y elige el alimento preferido.

Variación ontogénica.

Se ha observado que los juveniles y adultos de la lisa compartieron sus presas y no hicieron discriminación en cuanto a su alimentación fitoplanctónica y zooplanctónica, coincidiendo con lo observado en las aguas costeras del Océano Indico en África, donde la competencia interespecífica entre juveniles $\mathrm{y}$ adultos es probablemente impedida por el cambio rápido de carnívoros macrofagos planctónicos a bentónicos omnívoros

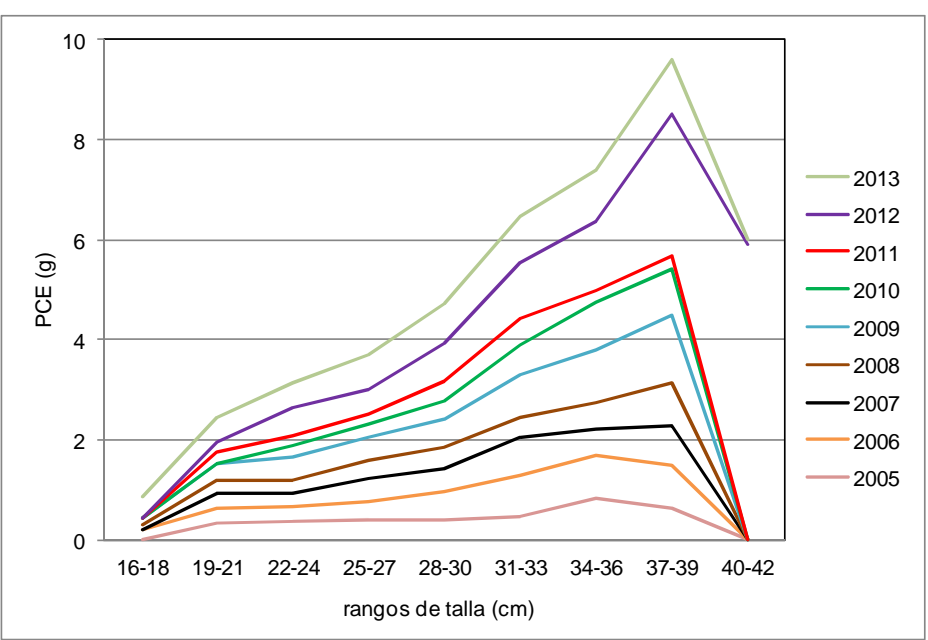

Figura 8. Distribución de frecuencia promedio de los pesos de contenido estomacal (g peso húmedo) por rangos de tallas de M. cephalus (promedio de 2005 al 2013 de Callao).

del lecho marino aspirando y arrastrando detritus, arena, diatomeas bentónicas y ocasionalmente copepodos (Thomson, 1964; Hendricks, 1961).

\section{Conclusión.}

Dado los hallazgos de esta investigación, se puede concluir que la dieta de lisa estaría sujeta a los cambios estacionales a diferencia de la anual y ontogénicamente no se observó mayor diferencia. Sus hábitos omnívoros y la oferta alimentaria le brindan un amplio espectro trófico.

\section{Agradecimientos.}

El presente estudio fue realizado en el Instituto del Mar del Perú (Laboratorio de Ecología Trófica), el material biológico 


\section{FERNÁNDEZ}

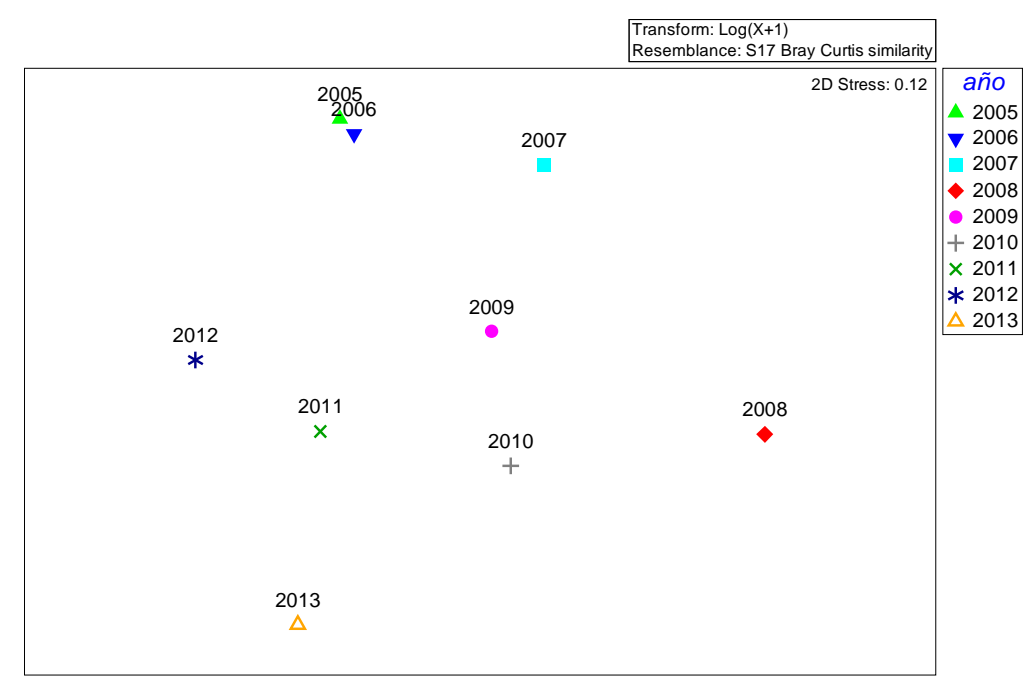

Figura 10. Análisis NMDS en 2D para los nueve años promedio, en la dieta de M. cephalus (2005 al 2013 de Callao).

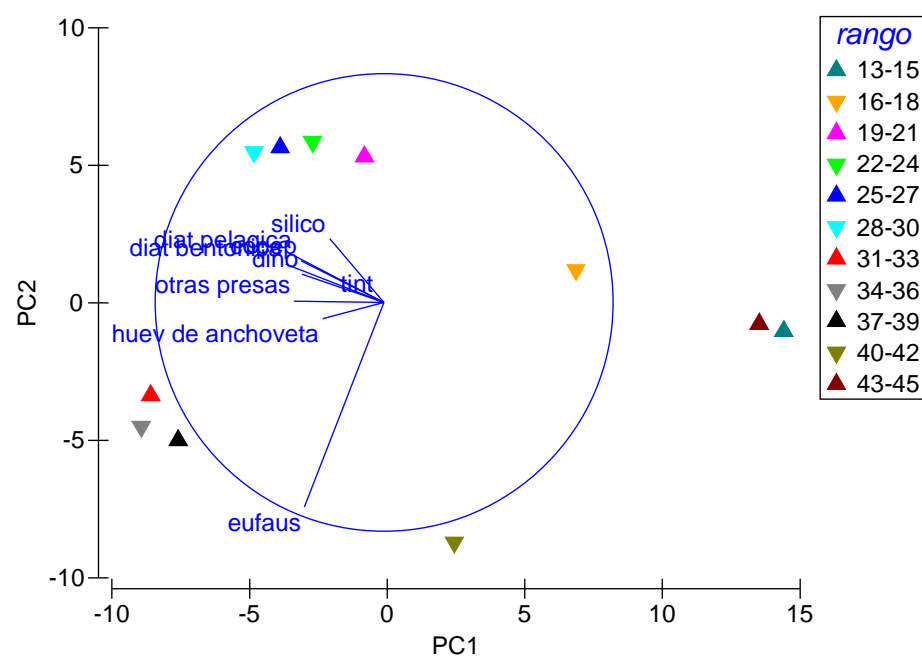

Figura 11. Análisis PCA por rangos de talla y grupos dietarios promedios, en la dieta de M. cephalus (2005 al 2013 de Callao).

procedió del Seguimiento de Pesquerías. Reconocimiento especial al Técnico Iván Navarro por su función analítica (zooplancton) y asesoría en el análisis de la información, al Mg. Sc. Pepe Espinoza (Laboratorio de Ecología Trófica) y al Blgo. Luis Quipuzcoa (Laboratorio de Bentos Marino); al Bach. en Estadística Willer Chanduvi (INEI) por los análisis estadísticos. Al Dr. Jorge Tam (Laboratorio de Modelado Oceanográfico, Ecosistémico y del Cambio Climático) y la M.Sc. Marilú Bouchon (Dirección de Investigaciones de Recursos Pelágicos) por la revisión de todo el manuscrito. Finalmente a la Lic. Marta Miyashiro (Universidad Católica del Perú) por la revisión de forma.

\section{Literatura citada.}

Akpan A. W. \& Isangedighi I. A. 2004. Aspects of the feeding ecology of three species of Pseudotolithus (Sciaenidae) in the inshore waters of Southeastern
Nigeria, East of the Niger Delta, Nigeria. Journal of Aquatic Science 19 (2) 51-58.

Alexandrov B.G. 2001. Caloric content of the Black Sea invertebrates: 1 Zooplankton and meiobenthos. In: Ecologiya Morya (Ecology of the Sea), ISSN:17266777, pp. 5-10 (in Russian).

Balech E. 1988. Los dinoflagelados del Atlántico Suboccidental. Pub. Esp. Inst. Español de Oceanografía, Madrid. $\mathrm{N}^{\circ} 1: 1-310$.

Berg J. 1979. Discussion of methods of investigating the food of fishes with reference to a preliminary study of prey of Gobiusculus flavescens (Gobiidae). Marine Biology 50: 263-273.

Blaber S.J.M \& Whitfield A. K. 1997. The feeding ecology of juvenile mullet (Mugilidae) in south-east African estuaries. Biological Journal of the Linnean Society Volume 9, Issue 3, pages 277-284.

Boltovskoy D. 1981. Atlas del zooplancton del Atlántico sudoccidental y métodos de trabajo con el zooplancton 
marino. Instituto Nacional de Investigación y Desarrollo Pesquero. Mar del Plata, Argentina. 936 p.

Borcard D. Gillet F. and Legendre P. 2011. Numerical Ecology with R. OSpringer Science+Business Media, LLC 2011.

Cardona L. 1990. Ecología trófica de los mugílidos (Osteichthyes: Mugilidae) en la Albufera des Grau (Menorca, Islas Baleares). Tesis de Licenciatura. Universidad de Barcelona.

Cardona L. 2001. Non-competitive coexistence between Mediterranean grey mullet: evidence from seasonal changes in food availability, niche breadth and trophic overlap. Journal of Fishery Biology, 59: 729-744.

Collins M.R. 1981. The feeding periodicity of striped mullet, Mugil cephalus L., in two Florida habitats. Department of Zoology, University of Florida, Gainesville, Florida 32611, U.S.A. Journal of Fishery Biology 19: 307-315.

Cupp E.E. 1943. Marine plankton diatoms of the west coast of North America. Bull. Scripps Institution of Oceanography 5 (1): 1-238.

Deibel D. 1986. Feeding mechanism and house of the appendicularian Oikopleura vanhoeffeni. Mar. Biol. 93, 429-436.

Drake P., Arias A. M. \& Gallego L.1984. Biología de los Mugílidos (Osteichthyes, Mugilidae) en los esteros de las salinas de San Fernando (Cádiz). III. Hábitos alimentarios y su relación con la morfometría del aparato digestivo. Investigaciones Pesqueras, 48 (2): 337-367.

El-Marakby, H.I., A. M. Eid, A. E. Abdelghany \& M. Abdel-Tawwab. 2006. The impact of striped mullet, Mugil cephalus on natural food and phytoplankton selectivity at different feeding regimes in earthen fishponds. Journal of Fishery Aquatic Science, 1 (1): 8796.

Fernández-Delgado C., A. Arias, D. García-Gonzáles y P. Drake. 2000. Peces de Doñana y su entorno. Organismo Autónomo de Parques Nacionales. Ministerio de Medio Ambiente, Madrid. 272.

Franco Luisa y Bashirullah K. M. B. 1992. Alimentación de la lisa (Mugil curema) del golfo de Cariaco - Estado Sucre, Venezuela. FONAIAP. Estación Experimental Falcón. Campo Experimental Las Piedras, estado Falcón. Instituto Oceanográfico-UDO. Cumaná, estado Sucre. Zootecnia Tropical. Vol. 10(2):219-238.

Gonzáles-Sansón G., y Álvarez-Lajonchere L. 1978. Alimentación natural de Mugil liza, M. curema, M. trichodon y $M$. hospes (Pisces, Mugilidae) en las lagunas costeras de Tunas de Zaza, Cuba. Ciencias Ser. 8 Invest. Mar. 41:40.

Hendricks L. J. 1961. The striped mullet Mugil cephalus Linnaeus. California Department of Fish and Game, Fishery Bulletin 113: 95-103.

Hildebrandt S. F. 1946. A descriptive catalog of the shore fishes of Peru. United States. Nat. Mus. Bull. 189: 1530.

Hyslop E.J. 1980. Stomach content analysis: a review of methods and their applications. Journal of Fishery Biology, Southampton, v. 17, no.4, 411-429.

IMARPE 2005. Anuario científico tecnológico vol 5. IMARPE 2006. Anuario científico tecnológico vol 6. IMARPE 2007. Anuario científico tecnológico vol 7. IMARPE 2008. Anuario científico tecnológico vol 8.
IMARPE 2009. Anuario científico tecnológico vol 9. IMARPE 2010. Anuario científico tecnológico vol 10. IMARPE 2011. Anuario científico tecnológico vol 11. IMARPE 2012. Anuario científico tecnológico vol 12.

ERFEN 2013. Boletín Alerta Climático Nº 273 (junio 2013).

James A.G. 1987. Feeding ecology, diet and field-based studies on feeding selectivity of the Cape anchovy Engraulis capensis Gilchrist. In: The Benguela and Comparable Ecosystems. Payne, A.I.L., Gulland, J.A. and K.H. Brink (Eds). South African Journal of Marine Science 5, 673-692.

Kesteven G.L. 1941. Conserving the mullet catch. Fishery Bulletin Western Australia (1): 1-14.

Koepcke H. 1955. Peces comunes de la costa peruana. 2da. Ed. Ser. Divulgación Científica $\mathrm{N}^{\circ} 6$.

Llanos J., 1974. Algunas consideraciones bioecológicas de la "lisa" Mugil cephalus L. en la Laguna de Medio Mundo. Tesis de grado, Programa de Ciencias Biológicas, Universidad Nacional de Trujillo, Perú.

Menden-Deuer, S., Lessard, E.J., 2000. Carbon to volume relationships for dinoflagellates, diatoms, and other protist plankton. Limnology and Oceanography 45, 569579.

Ochoa N. y O. Gómez 1986. Variación espacio temporal del fitoplancton frente a Callao, Perú en 1986. En: H. Salzwedel y A. Landa (eds): Recursos y dinámica del ecosistema de afloramiento peruano. Bol. Inst. Mar Perú. Vol. Extraordinario, 51-57.

Odum W.E. 1968. Mullet grazing on a dinoflagellats bloom. Chesapeake Sci. 9: 202-204.

Odum W.E. 1970. Utilization of the direct grazing and plant detritus food chains by the striped mullet (Mugil cephalus). In Marine Food Chains. (J.J. Steele ed.): 222240. Edinburgh.

Parsons, T.R., Takahashi, M., Hargraves, B., 1984. Biological Oceanographic Processes. Pergamon, Oxford

Quesquen \& Ayón. 2011. 5th International Zooplankton Production Symposium Population Connections, Community Dynamics, and Climate Variability March 14-18, 2011, Pucon, Chile (Panel).

Romer G.S. \& McLachalan A. 1986. Mulet grazing on surf diatom accumulations. Journal of Fishery of Biology, 28: 93-104.

Sameoto D. 1971. Life history ecological production and empirical mathematical model of the population of Sagitta elegans in St. Margaret's Bay Nova Scotia. Journal of Fisheries Research Board of Canada 28, 971985.

Sánchez J \& Zimic E. 1973. Historia Marítima del Perú, El Mar: Gran Personaje. Tomo I, Vol.2. 515-518.

Schiller J. 1971 Dinoflagellata (Peridinae) in monographischer Behandlung. In: L. Rabenhortst (ed). Kriptogamen-Flora von Deuchland, Osterreich und der Schweiz 2 Teil. Reprint by Johnson Repr. Corp. New York, Vol. 10, Section 3: 617.

Steidinger K. \& Tangen K. 1996. Dinoflagellates. In: Tomas C. (ed). Identifying Marine Diatoms and Dinoflagellates. Academic Press, Inc. San Diego: 387-570.

Theodorsson-Norheim, E. (1986). Kruskal-Wallis test: BASIC computer program to perform nonparametric one-way analysis of variance and multiple comparisons on ranks of several independent samples. Computer methods and programs in biomedicine, 23(1): 57-62. 


\section{FERNÁNDEZ}

Thomson J. M. 1964. The organs of feeding and the food of some Australia mullets. Australian J. Mar. freshwater Research 5: 469-486.

Verity P.G., Langdon, C. 1984. Relationships between lorica volume, carbon, nitrogen, and ATP content of tintinnids in Narragansett Bay. Journal of Plankton Research 6, 859-868.

Van der Lingen, C.D., 2002. Diet of sardine Sardinops sagax in the southern Benguela upwelling ecosystem. South African Journal of Marine Science 24, 301-316.
Verdiell-Cubedo D., Egea-Serrano A., Oliva-Paterna F.J. \& Torralva M. 2007. Biología trófica de los juveniles del género Liza (Pisces: Mugilidae) en la laguna costera del Mar Menor (SE Península Ibérica). Departamento de Zoología y Antropología Física, Facultad de Biología. Universidad de Murcia, 30100 Murcia, España. Limnetica, 26 (1): 67-73.

Wells R.D.S. 1984. The food of the grey mulIet (Mugil cephalus) in Lake Waahi and the Waikato river at Huntly. New Zealand Journal Marine Freshwater Research 18(1): 13-19.

Tabla 2. Frecuencia (nro. ind $\left.{ }^{-1}\right)$ y contenido de carbono $\left(\mu \mathrm{g}\right.$. ind $\left.\mathrm{in}^{-1}\right)$ promedio de especies presa encontrados en los estómagos analizados de Mugil cephalus (número de estómagos=3 268).

\begin{tabular}{|c|c|c|c|}
\hline Presas & $\begin{array}{c}\text { Distribución } \\
\text { vertical }\end{array}$ & $\begin{array}{c}\text { Frecuencia } \\
\left(\mathrm{n}^{\circ} \text { ind }^{-1}\right)\end{array}$ & $\begin{array}{r}\text { Carbono } \\
(\mu \mathrm{g} / \text { ind })\end{array}$ \\
\hline \multicolumn{4}{|l|}{ DIATOMEAS } \\
\hline Actinoptychus undulatus & pelágico & 1 & 0.001 \\
\hline Amphiprora sp. & bentónico & 1 & 0.0004 \\
\hline Amphora sp. & bentónico & 1 & 0.001 \\
\hline Asterionellopsis glacialis & pelágico & 3277 & 0.819 \\
\hline Asteromphalus heptactis & pelágico & 2 & 0.001 \\
\hline Cerataulina pelagica & pelágico & 1 & 0.002 \\
\hline Chaetoceros spp. & pelágico & 2139 & 1.258 \\
\hline Corethron hystrix & pelágico & 96 & 0.264 \\
\hline Coscinodiscus perforatus & pelágico & 17750 & 943.148 \\
\hline Detonula pumila & pelágico & 18588 & 70.852 \\
\hline Ditylum brightwellii & pelágico & 9792 & 45.602 \\
\hline Entomoneis alata v. alata & pelágico & 187 & \\
\hline Eucampia zoodiacus & pelágico & 8 & 0.009 \\
\hline Fragilariopsis doliolus & bentónico & 828 & 0.049 \\
\hline Grammatophora sp. & bentónico & 10581 & 10.381 \\
\hline Guinardia delicatula & pelágico & 9 & 0.092 \\
\hline Gyrosigma sp. & bentónico & 36298 & 213.281 \\
\hline Hemiaulus sp. & bentónico & 1 & 0.003 \\
\hline Licmophora abbreviata & bentónico & 72 & 0.098 \\
\hline Lithodesmium undulatum & pelágico & 507 & 0.432 \\
\hline Navicula sp. & bentónico & 32 & 0.020 \\
\hline Odontella longicruris & pelágico & 6389 & 9.157 \\
\hline Planktoniella sol & pelágico & 299 & 1.572 \\
\hline Pleurosigma sp. & bentónico & 6047 & 26.721 \\
\hline Proboscia alata v. alata & pelágico & 4 & 0.005 \\
\hline Pseudo-nitzschia pungens & pelágico & 4866 & 0.620 \\
\hline Pseudosolenia calcar-avis & pelágico & 99 & 3.069 \\
\hline Rhizosolenia sp. & pelágico & 35 & 0.253 \\
\hline Skeletonema costatum & pelágico & 20149 & 1.850 \\
\hline Stephanopyxis turris & pelágico & 245 & 1.675 \\
\hline Thalassionema nitzschioides & pelágico & 31362 & 6.621 \\
\hline Thalassiosira sp. & pelágico & 13509 & 20.726 \\
\hline Thalassiothrix frauenfeldii & pelágico & 2974 & \\
\hline centrice & pelágico & 4 & \\
\hline pennate & bentónico & 2308 & \\
\hline \multicolumn{4}{|l|}{ DINOFLAGELADOS } \\
\hline Ceratium spp. & $\begin{array}{l}\text { nerítico- } \\
\text { oceánico }\end{array}$ & 6827 & 106.311 \\
\hline Dinophysis caudata & nerítico & 1322 & 16.214 \\
\hline Gonyaulax sp. & oceánico & 3 & 0.039 \\
\hline
\end{tabular}


Tabla 2. Frecuencia (nro. ind $\left.{ }^{-1}\right)$ y contenido de carbono $\left(\mu \mathrm{g}\right.$. ind $\left.\mathrm{in}^{-1}\right)$ promedio de especies presa encontrados en los estómagos analizados de Mugil cephalus (número de estómagos=3 268).

\begin{tabular}{|c|c|c|c|}
\hline Presas & $\begin{array}{c}\text { Distribución } \\
\text { vertical }\end{array}$ & $\begin{array}{c}\text { Frecuencia } \\
\left(\mathrm{n}^{\circ} \text { ind }^{-1}\right)\end{array}$ & $\begin{array}{r}\text { Carbono } \\
(\mu \mathrm{g} / \text { ind })\end{array}$ \\
\hline Oxyphysis oxytoxoides & $\begin{array}{l}\text { nerítico- } \\
\text { oceánico }\end{array}$ & 77 & 0.886 \\
\hline Podolampas sp. & oceánico & 3 & 0.039 \\
\hline Prorocentrum sp. & $\begin{array}{l}\text { nerítico } \\
\text { nerítico- }\end{array}$ & 9672 & 46.280 \\
\hline Protoperidinium sp. & oceánico & 1680 & 51.751 \\
\hline Pyrophacus sp. & oceánico & 934 & 12.181 \\
\hline Scrippsiella trochoidea & nerítico & 19 & 0.211 \\
\hline \multicolumn{4}{|l|}{ SILICOFLAGELADOS } \\
\hline Dictyocha fibula & nerítico & 499 & 4.071 \\
\hline Octactis octonaria & nerítico & 761 & 5.949 \\
\hline \multicolumn{4}{|l|}{ Microzooplancton } \\
\hline \multicolumn{4}{|l|}{ TINTINIDOS } \\
\hline Amphorides sp. & & 2970 & 0.055 \\
\hline Eutintinnus sp. & & 390 & 0.007 \\
\hline Favella sp. & & 562 & 0.009 \\
\hline Helicostomella subulata & & 128 & 0.002 \\
\hline Tintinnopsis sp. & & 21 & 0.0004 \\
\hline Xystonella sp. & & 1 & 0.00001 \\
\hline \multicolumn{4}{|l|}{ Mesozooplancton } \\
\hline \multicolumn{4}{|l|}{ COPEPODOS } \\
\hline Acartia sp. & $\begin{array}{l}\text { nerítico } \\
\text { nerítico- }\end{array}$ & 20 & 0.228 \\
\hline Calanus sp. & oceánico & 1510 & 124.737 \\
\hline Calocalanus sp. & & 30 & 0.569 \\
\hline Centropages sp. & $\begin{array}{l}\text { nerítico- } \\
\text { oceánico } \\
\text { nerítico- }\end{array}$ & 920 & 33.163 \\
\hline Clausocalanus sp. & $\begin{array}{l}\text { oceánico } \\
\text { nerítico- }\end{array}$ & 1430 & 4.962 \\
\hline Corycaeus sp. & oceánico & 3080 & 22.200 \\
\hline Eucalanus sp. & nerítico & 170 & 103.783 \\
\hline Euterpina sp. & nerítico & 2710 & 4.604 \\
\hline Macrosetella sp. & nerítico & 90 & 0.289 \\
\hline Microsetella sp. & $\begin{array}{l}\text { nerítico } \\
\text { nerítico- }\end{array}$ & 1060 & 3.390 \\
\hline Oithona sp. & $\begin{array}{l}\text { oceánico } \\
\text { nerítico- }\end{array}$ & 15620 & 24.549 \\
\hline Oncaea sp. & $\begin{array}{l}\text { oceánico } \\
\text { nerítico- }\end{array}$ & 10986 & 31.344 \\
\hline Paracalanus sp. & oceánico & 1530 & 10.640 \\
\hline Harpacticoida & nerítico & 17352 & 46.468 \\
\hline Copepoditos & & 16179 & 25.714 \\
\hline Restos de copépodos & & 12150 & 3.407 \\
\hline Euphausiacea & $\begin{array}{l}\text { nerítico- } \\
\text { oceánico }\end{array}$ & 439 & 1901.885 \\
\hline \multicolumn{4}{|l|}{ Otros grupos } \\
\hline Mysidacea & $\begin{array}{l}\text { nerítico- } \\
\text { oceánico } \\
\text { nerítico- }\end{array}$ & 3 & \\
\hline Amphipoda & oceánico & 1 & 0.475 \\
\hline Bivalvia & nerítico & 222 & 25.064 \\
\hline
\end{tabular}




\section{FERNÁNDEZ}

Tabla 2. Frecuencia (nro. ind $\left.d^{-1}\right)$ y contenido de carbono $\left(\mu \mathrm{g}\right.$. ind $\left.{ }^{-1}\right)$ promedio de especies presa encontrados en los estómagos analizados de Mugil cephalus (número de estómagos=3 268).

\begin{tabular}{llrr}
\hline \multicolumn{1}{c}{ Presas } & $\begin{array}{c}\text { Distribución } \\
\text { vertical }\end{array}$ & $\begin{array}{c}\text { Frecuencia } \\
\left(\mathrm{n}^{\circ} \text { ind }^{-1}\right)\end{array}$ & \multicolumn{1}{c}{$\begin{array}{c}\text { Carbono } \\
(\mu \mathrm{g} / \mathrm{ind})\end{array}$} \\
\hline Gastropoda & $\begin{array}{l}\text { nerítico- } \\
\text { oceánico } \\
\text { nerítico- }\end{array}$ & 108 & 15.272 \\
Oceánico & & 10 & 0.016 \\
nerítico- & & 50 & 0.978 \\
Zoea & oceánico & 728 & 45.949 \\
Megalopa & nerítico & & \\
Huerítico- & oceánico & 520 & 15.845 \\
Huevos de anchoveta & & 50 & 2.170 \\
Huevos de pez n/i & & 114 & 5.077 \\
Huevos de crustaceos & nerítico & 3300 & 0.056 \\
Larvas de cirrípedos & nerítico & 219 & 0.001 \\
Larvas de equinodermos & & 69 & 147.942 \\
Larvas de pez n/i & & 14 & 1.488 \\
Chaetognata & & 40 & 3.178 \\
Decapoda reptantia n/i & & 140 & 147.170 \\
Restos de Myctophidae & & 110117 & \\
Restos orgánicos n/i & & 2241 & 849.805 \\
Polychaeta & & & \\
\hline
\end{tabular}

\footnotetext{
${ }^{1}$ Instituto del Mar del Perú. Laboratorio de Ecología Trófica. Esq. Gral. y Valle s/n Chucuito-Callao. Casilla Postal: Apartado 22. Correo electrónico: cfernandez@imarpe.gob.pe.
} 